\title{
EVALUATION OF THE NEW SOFTWARE PROGRAM DEGIFXL4 IN THE DETERMINATION OF THE GLYCAEMIC INDICES OF FOODSTUFFS
}

\author{
Helena Pribylova ${ }^{\text {a*}}$, Maria Pallayova ${ }^{\mathrm{b}}$, Jarmila Hucikova ${ }^{\mathrm{a}}$, Jiri Luza ${ }^{\mathrm{a}}$ \\ a Department of Physiology and $2^{\text {nd }}$ Department of Medicine, Faculty of Medicine and Dentistry, Palacky University, \\ 77515 Olomouc, Czech Republic \\ ${ }^{b}$ Department of Physiology and $1^{\text {st }}$ Department of Medicine, Faculty of Medicine, P. J. Šafárik University, Košice, Slovak \\ Republic \\ e-mail:p.helca@seznam.cz
}

Received: August 8, 2008; Accepted (with resivions): October 10, 2008

Key words: Nutrition/Glycaemic index/Continuous glucose monitoring/Data processing/DegifXL software

Aims: There is no standardized protocol for measuring glycemic index (GI) that takes time-of-day effects into account. The software DegifXL2 and Medtronic-Minimed's CGMS ${ }^{\mathrm{TM}}$ and Solutions ${ }^{\mathrm{TM}}$, makes the GI calculation at breakfast and dinner time possible. The aim of this study was to assess the enhanced data processing software (DegifXL4) enabling the GI calculation at breakfast, lunch, afternoon snack and dinner times.

Methods: The glucose levels of 20 healthy volunteers were monitored after they consumed either $50 \mathrm{~g}$ of glucose or one of ten alternative foodstuffs either for breakfast and dinner or for lunch or snack. Within the 9-day test period, 10 such meals were monitored in 3 replicates for each volunteer. Specifically, CGMS ${ }^{\mathrm{TM}}$ was used to monitor plasma glucose levels at 5-minute intervals for a period of $120 \mathrm{~min}$ following the foodstuff ingestion.

Results: Using the enhanced spreadsheed DegifXL 4, a total of 640 profiles were obtained and 491 (77 \%) accomplished the criteria for further processing. The percentage of successful tests in each foodstuff varied from 57 to $87 \%$.

Conclusions: The use of the new software DegifXL4 offers accurate GI estimates for foodstuffs eaten for breakfast, lunch, snacks and dinners in three replicates. In combination with the CGMS Solutions Software ${ }^{\mathrm{TM}}$ is DegifXL4 an enhanced efficient and comfortable way to routinely measure GI values.

\section{INTRODUCTION}

The glycaemic index of food (GI) is conventionally defined as the ratio of the area under the fingerprick 7-point glycaemic curve (AUC) of the tested food to the AUC of the standard (glucose); both areas are calculated for a 120 min-interval after the food ingestion. Within this period, the commercially available continuous glucose monitoring system $\left(\mathrm{CGMS}^{\mathrm{TM}}\right)$ gives a total of 25 values of an individual's interstitial fluid glucose concentration (ISFG) ${ }^{1}$. There is no significant difference between the GI values obtained by the CGMS ${ }^{\mathrm{TM}}$ and values obtained by more time-consuming conventional methods, and both methods have high variability'. Using the software DegifXL2 and Medtronic-Minimed's CGMS ${ }^{\mathrm{TM}}$ and Solutions ${ }^{\mathrm{TM}}$, the GI calculation at breakfast and dinner times is possible ${ }^{2}$. To enhance the capacity of the GIs investigating centre, DegifXL was adapted to enable the detemination of the GI also at lunch- and snack- times. The aim of this study was to assess the new data processing software (DegifXL4) enabling the GI calculation at breakfast, lunch, afternoon snacks and dinners.

\section{MATERIAL AND METHODS}

The procedures used in this study were in accordance with the Helsinki Declaration of 1975 as revised in 2000, and were approved by the local Ethics Committee.

Twenty-five healthy volunteers entered the study and 20 aged $21.94 \pm 1.39$ y (mean \pm SE), 7 men, 13 women, completed it. Informed written consent was obtained from all volunteers.

The tested software program DegifXL4 is based on the principles of the program DegifXL2. Both programs were developed at the Faculty of Medicine, Palacký University, Olomouc, Czech Republic ${ }^{2}$, using Microsoft Excel 2000 (Microsoft Corporation, Redmond, WA, USA). To use this program, the following is required: 1) A team of trained investigators (comprising physicians, educators, dietitians, lab workers, IT support workers); 2) Trained testers who are familiar with the use of CGMS ${ }^{\mathrm{TM}}$ and the terms of the study protocol (at least one tester is required); 3) Exact portions of foods to be tested, each containing $50 \mathrm{~g}$ of absorbable carbohydrates; 4) The necessary hardware: a PC, CGMS ${ }^{\mathrm{TM}}$, glucometers; 5) The necessary software (MS Excel 2000, CGMS Solutions Software ${ }^{\mathrm{TM}}$ and DegifXL4). 


\section{Test period design}

In this study, each volunteer consumed $50 \mathrm{~g}$ of glucose or one of ten alternative foodstuffs for breakfast and dinner, for lunch and for afternoon snacks. Exceptionally, juice or chips were consumed, if other foods were not available. Thirty-two tests were performed on each of the 20 volunteers; the test period began in the evening of the first day and continued for the following 8 days, one test in the morning (breakfast), at noon (lunch), one test in the afternoon (snack) and one test in the evening (dinner).

The subjects were encouraged to consume one portion of the test meal within 30 minutes. During the day they were not allowed to eat any other meal. They were asked to fast for 4 hours before breakfast, lunch, snack and dinner tests, respectively. All meals were designed for scheduled tests only.

\section{$C G M S^{T M}$ operation}

The operations are similar to those in DegifXL2 as was described elsewhere ${ }^{3}$. The CGMS sensor was inserted before the first test meal and remained inserted throughout the whole test period. At the beginning of each test meal, the tester entered the event 'FOOD' into the monitor. If this step was omitted, the meal start time had to be entered into 'DATA' at a later time, since tests lacking the meal start time can not be processed.

\section{Transfer of data to the DegifXL spreadsheet}

Subjects' ISFG data was exported from the CGMS Solutions Software ${ }^{\mathrm{TM}} 7310$ v. 3.0C (Medtronic-Minimed, Northridge, CA, USA) at the end of the test period, which in this study was day 9 . Each subject was identified by a number or name.

\section{Mathematical principles and formulas}

The IAUC was determined using calculus (integration, as the sum of the trapezoid areas) according to the formula (Fig. 1): IAUC $=\sum \mathrm{S}_{\mathrm{i}} \mathrm{i}=1, \ldots, 24$, where

$\mathrm{S}_{\mathrm{i}}=\frac{\left(\mathrm{G}_{\mathrm{i}}-\mathrm{G}_{0}\right)+\left(\mathrm{G}_{\mathrm{i}-1}-\mathrm{G}_{0}\right)}{2} \cdot \Delta \mathrm{t}$

$\mathrm{G}_{\mathrm{i}}$ : glucose concentration at a particular time; $\mathrm{G}_{0}$ : starting glucose concentration; and $\Delta t=5 \min$. For $G_{i}<G_{0}$, $\mathrm{S}_{\mathrm{i}}=0$.

The GI calculation for each test food was carried out in every test subject separately according to the formula:

$G I=\frac{\text { average } \mathrm{IAUC}_{\text {test food }}}{\text { average } \mathrm{IAUC}_{\text {glucose }}} .100[\%]$

The group-averaged GI for the test food can be calculated from all the individuals' calculated GIs.

\section{Data processing in DegifXL}

The current version of DegifXL consists of four spreadsheets, named SETUP, DATA, LIST OF PROBANDS, AND STATISTICS. Having opened the SETUP sheet of DegifXL (Fig. 2), the user has to fill in or revise the following data:
- The total number of tests planned for one individual

- The exact path to the directory ".fst"

- The lower limit for ISIG (Input Signal of Glucose) in the CGMSTM.

- The limit for missing ISFG values in one test

- The list of tested foods (Table 1) and their abbreviations (Marks).

- Test meal times for morning, noon, afternoon and evening tests into a separate table [Test meal time].

- The number of the test meal in the test schedule must be input into [Order of meal in test]. This function allows the averaged GI values to be calculated for specific foods from a given test.

- Optional marks into [Other rank] when needed to select meals according to specific criteria (e.g., GI for fresh meals); the GI value is calculated if the mark is entered into the raw [Filter values] and may be found in the STATISTICS spreadsheet (Figs. 5a, b).

The DATA spreadsheet (Fig. 3) imports data from a .fst file when the user clicks on the button [Import CGMS]. The missing start times must be filled in manually, according to tester's protocol. Any events introduced into the CGMS monitor by mistake of the tester (e.g. event FOOD at lunch time when no test meal was served) have to be deleted. By clicking on the button [Resulting IAUC], the values of IAUC, which are calculated from the ISFG values of the individual tests, appear on the screen. The data of the next tester can then be added as described above. The table in the upper part of the DATA spreadsheet shows the number of successful tests with each type of food, the number of persons successfully completing all planned tests (in this study, 3 tests with each food), and the number of people completing one or two tests.

The spreadsheet PROBAND LIST (Fig. 4) shows an overview of the number of successful tests carried out with individual foods selected in this sheet and in the SETUP spreadsheet. The selection of probands (e.g., according to sex and/or diabetes type and/or other user-defined parameters) is performed by entering the filter parameter (to be designed by the user) into the row [Filter].

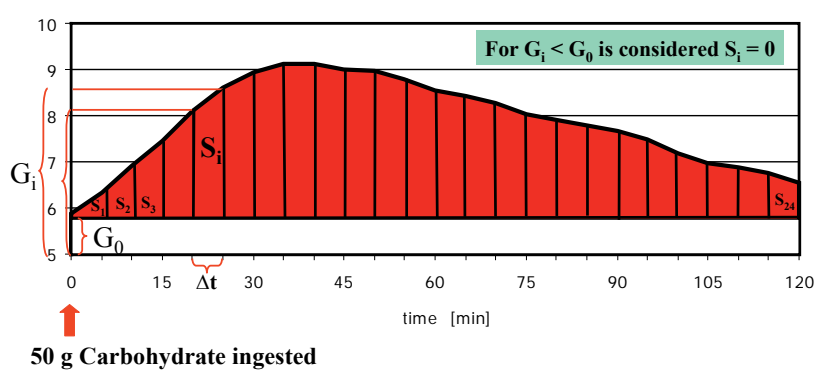

Fig. 1. Calculating the incremental area under the curve (IAUC). $\mathrm{G}_{0}$ : glucose concentration before meal intake; $\mathrm{G}_{\mathrm{i}}$ : glucose concentration at a particular time; $\Delta \mathrm{t}$ : time interval between estimations (in $\mathrm{CGMS}^{\mathrm{TM}}$, always $5 \mathrm{~min}$ ); $\mathrm{S}_{\mathrm{i}}$ : surface of the respective trapezoid. 


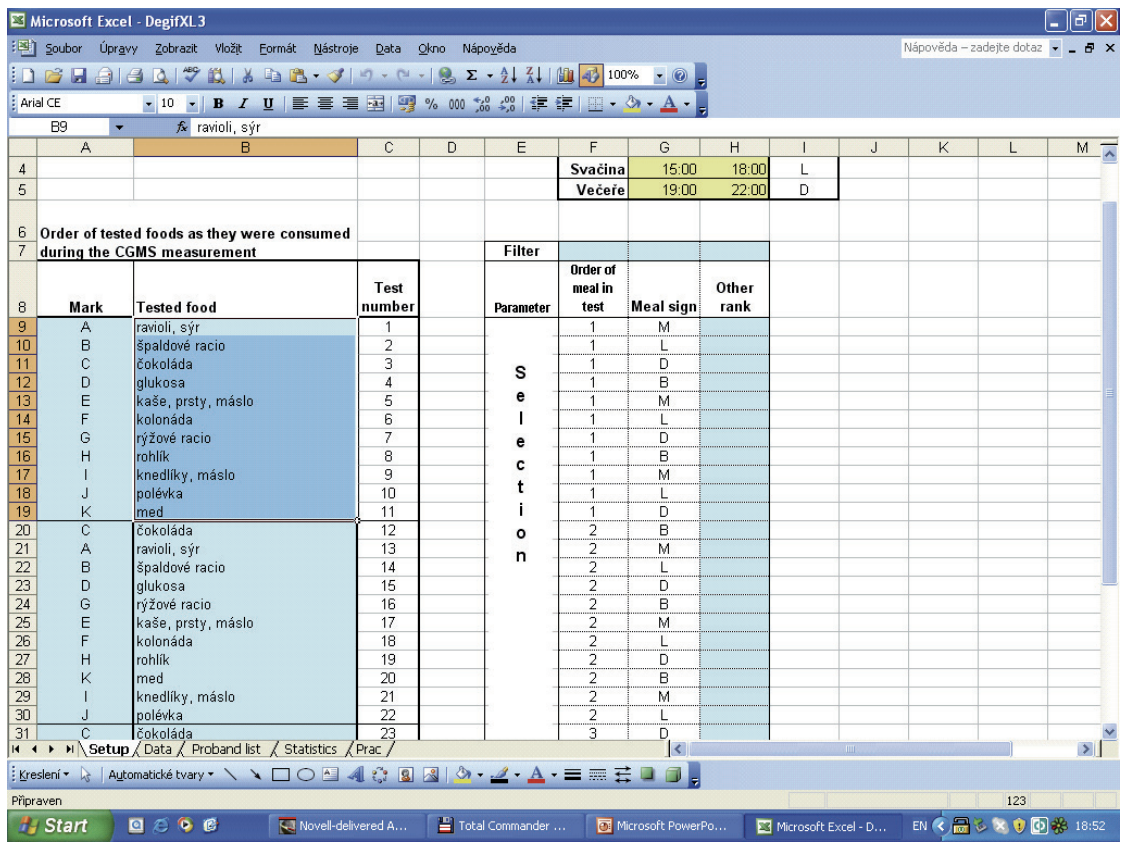

Fig. 2. Example of the SETUP spreadsheet, which is completed at the beginning of the analysis. ISIG shows the intensity of electrical current from the $\mathrm{CGMS}^{\mathrm{TM}}$ sensor, thus reflecting the glucose concentration.

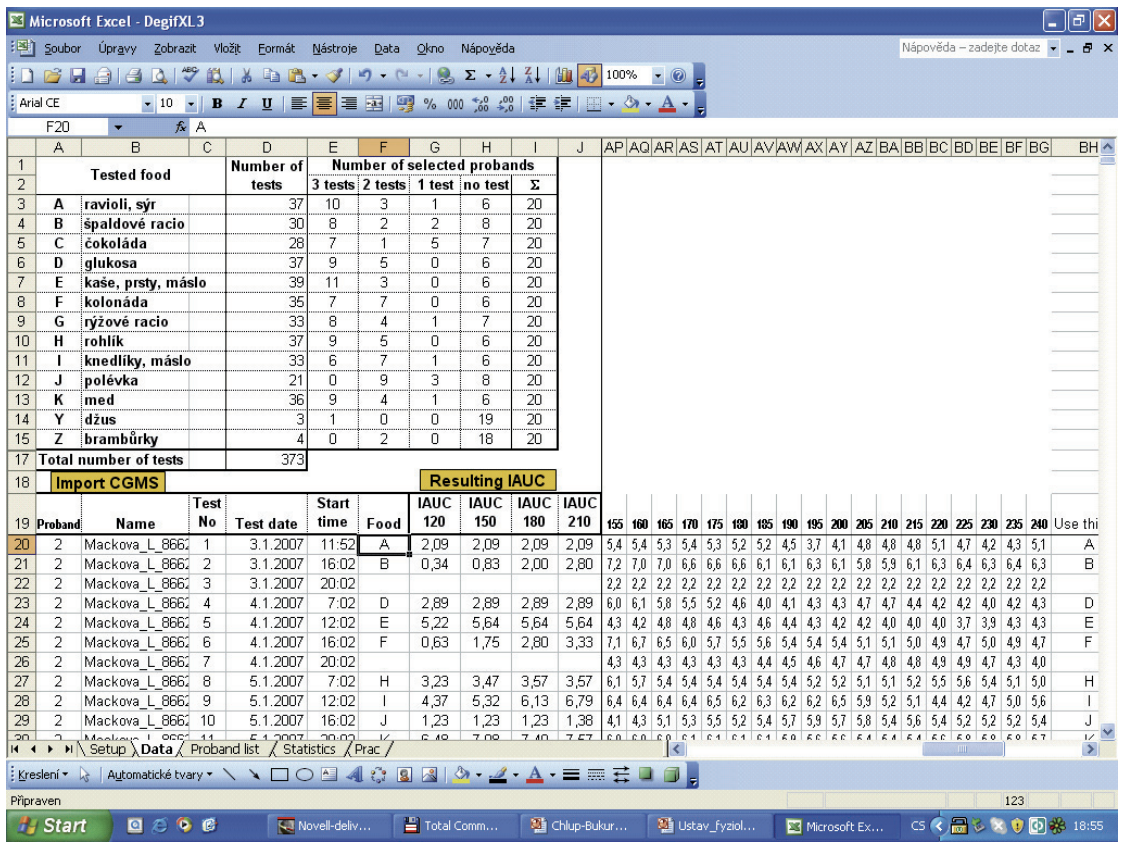

Fig. 3. Example of the DATA spreadsheet, which is generated by clicking on [Import CGMS].

The most important DegifXL results can be found in the STATISTICS spreadsheet (Fig. 5). The following data are shown:

- The group-averaged GI, the number of test subjects, the number of successful tests performed with individual foods, and the average IAUC for the entire group of all subjects tested.

- The individual subject-related GI and the number of successfully processed tests performed with tested foods in one selected individual. The individual is selected by clicking on the personal identification number in the yellow field [Prob. No].

\section{Assessment of DegifXL 4}

The newly developed DegifXL4 software was asessed by processing the CGMS ${ }^{\mathrm{TM}}$ data obtained from 20 volunteers. The efficiency of using the CGMS ${ }^{\mathrm{TM}} /$ DegifXL software was considered to be the percentage of successfully processed tests from the total number of tests. 


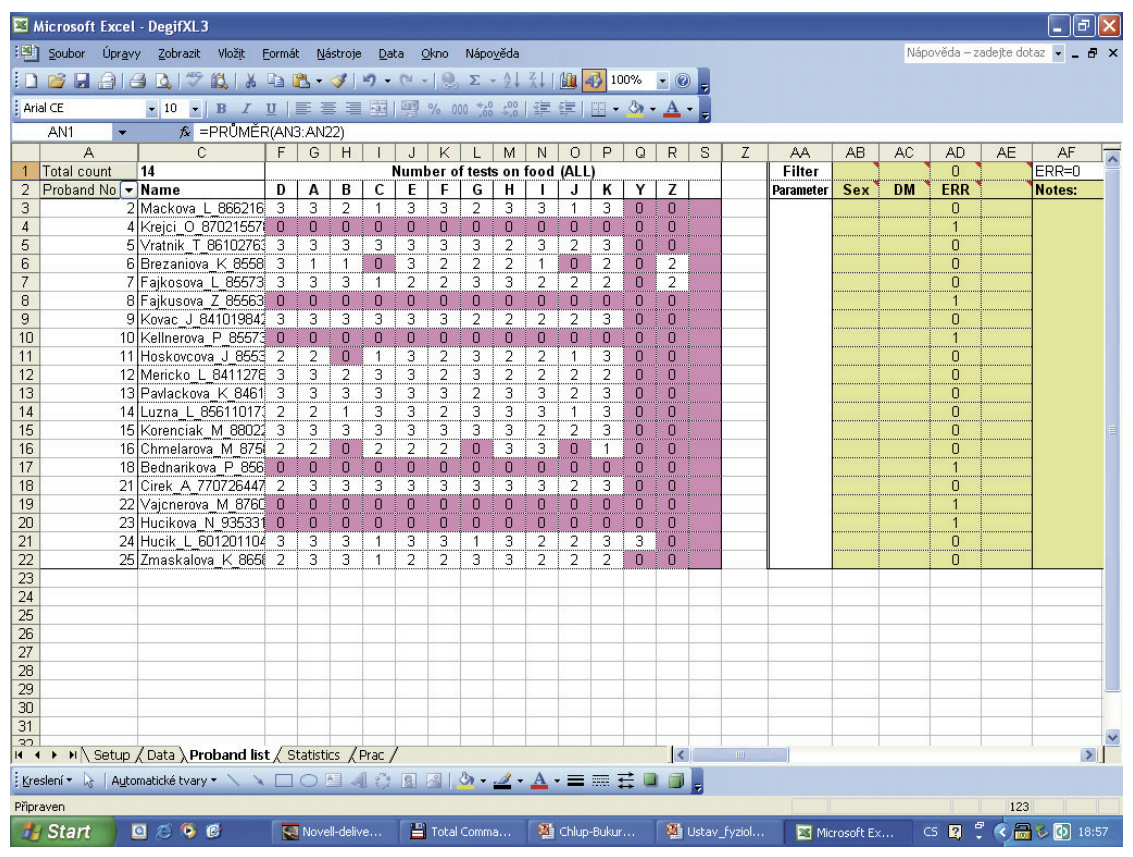

Fig. 4. Example of the PROBAND LIST spreadsheet. Probands are selected in the table on the right.

Table 1. Number of tests with individual foodstuffs which have reached the evaluation criteria and number of probands which have successfully accomplished 3,2 or one tests. All tests that have not fullfilled the evaluation criteria are automatically excluded from further processing.

\begin{tabular}{|c|c|c|c|c|c|c|c|c|}
\hline \multirow[t]{2}{*}{ Foodstuff } & \multirow{2}{*}{$\begin{array}{l}\text { Number } \\
\text { of per- } \\
\text { formed } \\
\text { tests }\end{array}$} & \multicolumn{2}{|c|}{$\begin{array}{l}\text { Number of suc- } \\
\text { sessful tests to } \\
\text { be processed }\end{array}$} & \multicolumn{5}{|c|}{ Number of probands } \\
\hline & & Abs. & $\%$ & 3 tests & 2 tests & 1 tests & $\begin{array}{l}\text { No } \\
\text { test }\end{array}$ & $\mathrm{n}$ \\
\hline Ravioli pasta, Cheese & 60 & 48 & 80.0 & 11 & 6 & 3 & 0 & 20 \\
\hline Spelt squares & 60 & 41 & 68.3 & 10 & 3 & 5 & 2 & 20 \\
\hline Dark Chocolate & 60 & 34 & 56.7 & 8 & 1 & 8 & 3 & 20 \\
\hline Glucose & 60 & 50 & 83.3 & 12 & 6 & 2 & 0 & 20 \\
\hline Mashed potatoes, fish fingers, butter & 60 & 52 & 86.7 & 15 & 3 & 1 & 1 & 20 \\
\hline Kolonáda wafers & 60 & 44 & 73.3 & 9 & 8 & 1 & 2 & 20 \\
\hline Rice squares & 60 & 45 & 75.0 & 10 & 5 & 4 & 1 & 20 \\
\hline Roll & 60 & 50 & 83.3 & 12 & 7 & 0 & 1 & 20 \\
\hline Apricot dumplings, butter & 60 & 41 & 68.3 & 6 & 10 & 3 & 1 & 20 \\
\hline Tomato soup & 40 & 28 & 70.0 & 0 & 12 & 4 & 4 & 20 \\
\hline Honey & 60 & 48 & 80.0 & 12 & 5 & 2 & 1 & 20 \\
\hline Juice & $\mathrm{n} / \mathrm{a}$ & 6 & & 2 & 0 & 0 & 18 & 20 \\
\hline Chips & $\mathrm{n} / \mathrm{a}$ & 4 & & 0 & 2 & 0 & 18 & 20 \\
\hline Total number of tests & 640 & 491 & 76.7 & & & & & \\
\hline
\end{tabular}

n/a not applicable (juice and chips were eaten in case of intolerance of planned food). 

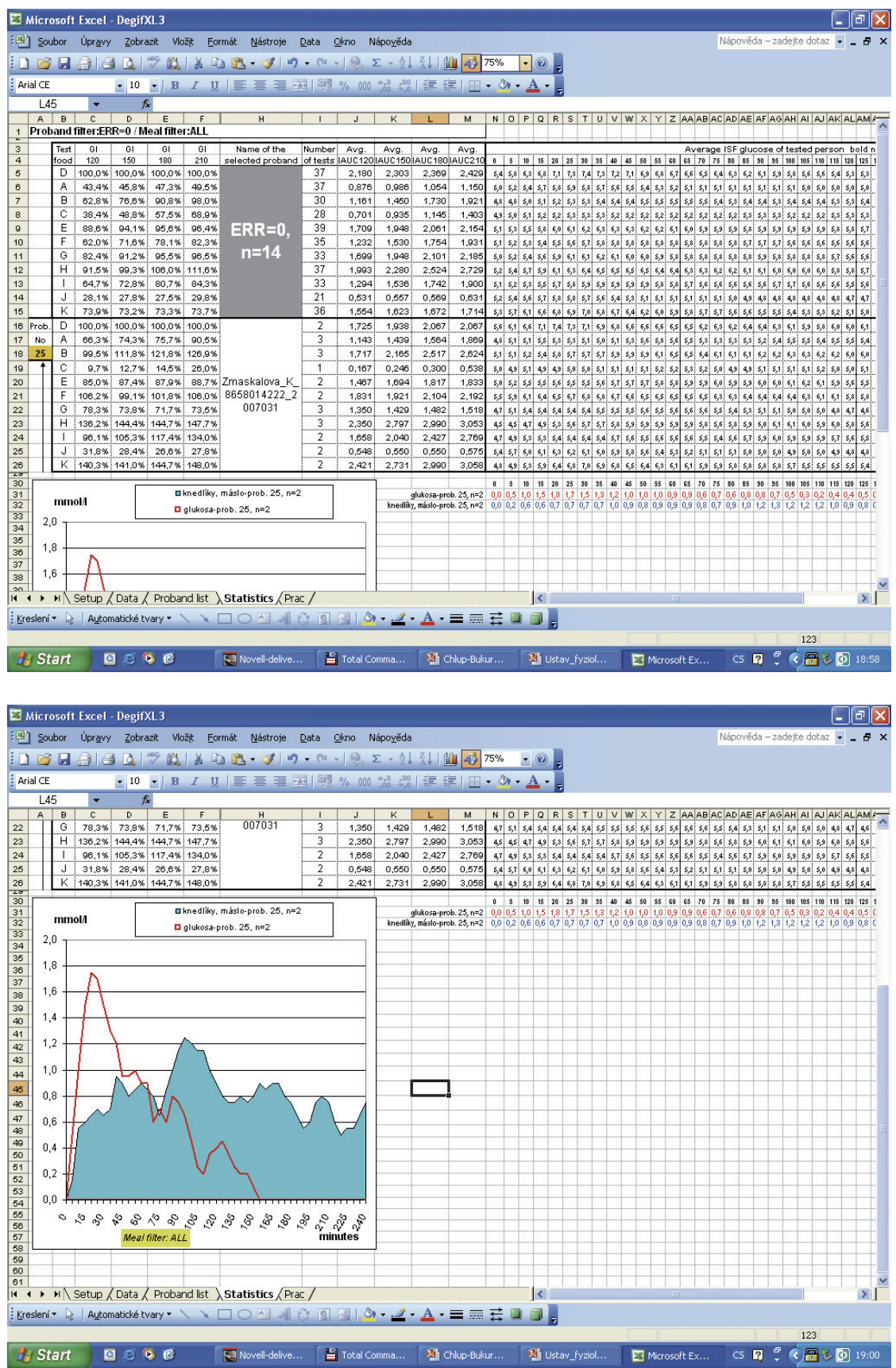

Fig. 5. Example of the STATISTICS spreadsheet, which shows the groupaveraged GIs and IAUCs of the whole group of 20 volunteers and the person-related GI's of a selected volunteer. a. upper part of the screen, b. lower part of the screen.

\section{RESULTS}

To evaluate the software and protocols used in this study, we determined the number of tests performed from which we obtained usable data (i.e. the efficiency of the test). Using the CGMSTM/DegifXL4 System, there were 491 successful tests ( $77 \%$ ) from the 640 tests performed in the group of 20 healthy volunteers (Table 1). Each of the 11 foods (except soup) was tested in 3 replicates in each of the 20 volunteers, i.e. 60 tests were performed with each food. However, only complete tests performed under standardized conditions were processed. The number of successfully processed tests for the particular foods ranged from $34(56.7 \%)$ to $52(86.7 \%)$. The test failures were tester-related $(n=47$; i.e. $7 \%)$ or CGMS $^{\mathrm{TM}}$ related $(n=102$; i.e. $16 \%)$.

\section{DISCUSSION}

Since 1973, the concept of GI was introduced step by step into clinical practice ${ }^{4-9}$. In 1998, the WHO and FAO reccommended including GI values into nutrition tables ${ }^{10}$. 
Conventional methods for calculating GI have been described and widely used, studying 10 healthy subjects on multiple occasions in the morning after a $10-14 \mathrm{~h}$ overnight fast. Subjects are asked to do no unusually vigorous activities on the day before the test, to drink no alcohol and not to smoke for $24 \mathrm{~h}$ before the test. After a fasting blood sample, subjects eat a test meal and have further blood samples at 15, 30, 45, 60, 90 and 120 minutes after starting to eat. Capillary blood is obtained by finger-prick and whole blood glucose determined with an automatic analyzer using the glucose oxidase method. Each test meal contains $50 \mathrm{~g}$ available carbohydrate (total carbohydrate minus dietary fiber). The GI is valid as a method of classifying the plasma glucose responses of high carbohydrate foods. To test low carbohydrate foods, meals containing smaller amounts of carbohydrate may be used, but the amount of reference food should be adjusted so that it contains the same amount of available carbohydrate as the reference food. A drink of the subject's choice is served with each test meal. The subject can chose to have 1-2 cups of water, coffee or tea, with $30 \mathrm{ml} 2 \%$ milk per cup if desired. However, the drink chosen by the subject is the same for every test performed. Test meals are consumed within 10 minutes. Each subject conducts one trial of each test food and 3 trials of the reference food. The reference food can be anhydrous glucose or white brad. Typically the reference food trials are done at the beginning middle and end of the series of tests, with the order of the test foods randomized between the reference foods. If large numbers of foods are being tested, a reference food trial should be done for every 5-6 test foods (to ensure no changes in subject's glucose responses with time). There are many ways to calculate the AUC, and the method used affects the GI value obtained. Assuming that at times $\mathrm{t}_{0}, \mathrm{t}_{1}, \ldots \mathrm{t}_{\mathrm{n}}$ (here equalling $0,15 \ldots 120 \mathrm{~min}$, respectively) the blood glucose concentrations are $G_{0}, G_{1}$, $\ldots \mathrm{G}_{\mathrm{n}}$, respectively.

$$
\mathrm{AUC}=\Sigma \mathrm{A}_{\mathrm{x}}
$$$$
\mathrm{x}=1
$$

$\mathrm{n}$

Where $A_{x}=$ the AUC for the xth time interval and the $x$ th time interval is the interval between times $t_{(x-1)}$ and $t_{x}$.

At the Faculty of Medicine, Palacký University, Olomouc, new software DegifXL was developed and succesfully used to determinate GI at breakfast and dinner times ${ }^{3}$. Published GI tables ${ }^{11}$ show group-averaged GIs only, and the large variability in the GIs is ascribed to various factors ${ }^{12-14}$. The terms "group-averaged GI" and "subject-related GI" were used in order to distinguish GIs obtained from a group versus a GI obtained from an individual. Determination of individual subject-related GI has improved our understanding of metabolic processes ${ }^{9,15-16}$. It is also a useful concept in relation to physical exercise ${ }^{17}$ and to occupational activities ${ }^{18}$.

In the present study, in order to increase the capacity of the investigational process, the enhanced software
DegifXL4 involves not only breakfasts and dinners but also lunches and snacks ${ }^{19-20}$. Nevertheless, the accuracy of the GIs determined at lunch- snack- and dinner times remains to be established. As it was not easy to consume the demanded amount of dark chocolate within 10 minutes, the period of food intake was prolonged to 30 minutes. The Glucometer Advance System ${ }^{21}$ was used to calibrate the $\mathrm{CGMS}^{\mathrm{TM}}$. The CGMS ${ }^{\mathrm{TM}}$ sensor remained inserted for up to 9 days ${ }^{22-26}$ without serious adverse reactions.

Clinically, it is important to evaluate the glycaemic profiles of individuals with diabetes in response to a given food/mixed meal in combination with a particular treatment ${ }^{27-33}$ - i.e. the glycaemic response to a complex food such as pizza.

The strength of this new protocol is that it automates GI calculation for four meals a day taken in a group of about 20 or more volunteers in a test period of several days. The data can be analyzed in greater detail using a statistical program such as SPSS v. 14 (SPSS Inc., Chicago, USA). Use of DegifXL4 is quite simple. However, routine determination of GI should be carried out in specialized centers staffed by qualified professionals who have been properly trained ${ }^{34}$.

To summarize, the use of the new software DegifXL4 offers accurate GI estimates for foodstuffs taken in three replicates for breakfasts, lunches, snacks and dinners. DegifXL4 in combination with the CGMS Solutions Software $^{\mathrm{TM}}$ is an enhanced efficient and comfortable way to routinely measure GI values. Further practice-oriented studies are necessary to find the relation between the GI at different meal times.

\section{ACKNOWLEDGEMENTS}

Supported by Research Project IGA NR 7825-3, Ministry of Health, Czech Republic. Parts of this study were presented at the XL. Conference of Student scientific activities, Faculty of Medicine and Dentistry, Palacky University, Olomouc, 28-29.5.2007.

\section{REFERENCES}

1. Chlup R, Jelenová D, Kudlová P, Chlupová K, Bartek J, Zapletalová J, Langová K, Chlupová L: Continuous glucose monitoring - a novel approach to the determination of the glycaemic index of foods (DEGIF 1). Exp Clin Endocrinol Diabetes 2006; 114:6874.

2. Chlup R, Sečkař P, Zapletalová J, Langová K, Kudlová P, Peterson K, Bartek J, Hučíková J. DegifXL - a new software program for determination of group-related and person-related glycemic indexes of foods by means of continuous glucose monitoring system CGMS. Acta Diab. Romana 2007; 33(1)1:351 (Abstract).

3. Chlup R, Sečkař P, Zapletalová J, Langová K, Kudlová P, Chlupová $\mathrm{K}$ et al. Automated computation of glycemic index for foodstuffs using continuous glucose monitoring. J Diabetes Sci Technol 2008;2(1)

4. Otto H, Bleyer G, Pennartz M, Sabin G, Schauberger G, Spaethe R: Kohlenhydrataustausch nach biologischen Äquivalenten. In: Otto H, Spaethe R (Ed). Diätetik bei Diabetes mellitus [German: Exchange of Carbohydrates according to biological equivalents. In: 
Otto H, Spaethe R (Ed). Diet in diabetes mellitus]. Verlag Hans Huber, Bern Stuttgart Wien. 1973:41-50.

5. Jenkins DJA, Wolever TMS, Taylor RH, Barker H, Fielden H, Baldwin JM, Bowling AC, Newman HC, Jenkins AL, Goff DV: Glycemic index of foods: a physiological basis for carbohydrate exchange. Amer J Clin Nutr 1981; 34:362-366.

6. Ionescu-Tirgoviste C, Popa E, Santu E, Mihalache N, Cheta D, Mincu I: Blood glucose and plasma insulin responses to various carbohydrates in type 2 (non-insulin-dependent) diabetes. Diabetologia 1983; 24:80-84.

7. Bruns W: Behandlung mit Diät. In: Bibergeil H (Ed). Diabetes mellitus. Ein Nachschlagewerk für die diabetologische Praxis [German: Diet treatment. In: Bibergeil H (Ed). Diabetes mellitus. Guidelines for the diabetes practice]. VEB Gustav Fischer Verlag Jena. 1989:254-316.

8. Chantelau E: The glycaemic index of carbohydrate foods: an update from a diabetologist's perspective. Aktuel Ernaehr Med 2000; 25:176-185.

9. Jenkins DJA, Kendall CWC, Augustin LSA, Silvia Franceschi, Hamidi M, Marchie A et al. Glycemic index: overview of implications in health and disease. Am J Clin Nutr 2002; 76:266-273.

10. Food and Agriculture Organization/World Health Organization. Carbohydrates in human nutrition: report of a Joint FAO/WHO expert consultation. FAO Food and Nutrition Paper 1998; 66:1140.

11. Foster-Powell K, Holt SH, Brand-Miller JC. International table of glycemic index and glycemic load values. Amer J Clin Nutr 2002; 76:5-56.

12. Wolever TM, Csima A, Jenkins DJ, Wong GS, Josse RG. The glycemic index: variation between subjects and predictive difference. J Am Coll Nutr 1989; 8(3):253-47.

13. Nell T, Venter Ch, Vorster H, Botes I, Steyn F. Intra- and interindividual variation in glucose response to white bread and oral glucose in healthy women. SAJCN 2003; 16:58-64.

14. Chlup R, Bartek J, Rezníčková M, Zapletalová J, Doubravová B, Chlupová $\mathrm{L}$ et al. Determination of the glycaemic index of selected foods (white bread and cereal bars) in healthy persons. Biomed Papers 2004; 148:17-25.

15. Brand-Miller JC, Holt SH, Pawlak DB, McMillan J. Glycemic index and obesity. Am J Clin Nutr 2002; 76(1):281S-5S.

16. Pi-Sunyer FX. Glycemic index and disease. Am J Clin Nutr 2002; 76(1):290S-8S

17. Thomas DE, Brotherhood JR, Brand JC. Carbohydrate feeding before exercise: effect of glycemic index. Int J Sports Med 1991; 12(2):180-6.

18. Nakládalová M, Kapoun S. Zdravotní způsobilost k práci u osob $\mathrm{s}$ diabetem. [Czech: Occupational ability in persons with diabetes] Pracovní Lék 2004; 56:13-16.

19. Granfeldt Y, Wu X, Björck I. Determination of glycaemic index; some methodological aspects related to the analysis of carbohydrate load and characteristics of the previous evening meal. Eur J Clin Nutr 2006; 60:104-112.

20. Wolever TMS, Vorster HH, Bjorck I, Brand-Miller J, Brighenti F, Mann JI et al.. Determination of the glycaemic index of foods: interlaboratory study. Eur J Clin Nutr 2003; 57:475-482.
21. Chlup R, Payne M, Zapletalová J, Komenda S, Doubravová B, Řezničková $\mathrm{M}$ et al. Results of selfmonitoring on glucometer systems Advance and Optium in daily routine. Biomed Papers 2005; 149:127-139.

22. Chlup R., Bartek J, Malá E, Doubravová B, Pukowietz L, Zatloukal $P$ et al. Uživatelská studie o správnosti a přesnosti měření glukometrů Advance, Card a Optium (Useroriented study on accuracy and precision of glucometer systems Advance, Card and Optium). Klin Bioch Metabol 2004; 12:171-178.

23. Chlup R, Jelenová D, Chlupová K, Zapletalová J, Chlupová L, Bartek J: Function and accuracy of glucose sensors beyond their stated expiry date. Diabetes Technology\&Therapeutics 2006; 8:495504.

24. Jadviščoková T, Fajkusová Z, Pallayová M, Luža J, Kuzmina G. Occurence of adverse events due to continous glucose monitoring. Biomed Papers 2007; 151 (2):263-267.

25. Fajkusová Z, Jadviščoková T, Pallayová M, Luža J, Kuzmina G. Glycaemic index of selected foodstuffs in healthy persons. Biomed papers 2007; 151(2):257-263.

26. Peterson K, Chlup R, Kudlová P, Slezáková L, Zapletalová $\mathrm{J}$, Langová $\mathrm{K}$ et al. Influence of Oral Antidiabetic Drugs on Hyperglycemic Power of Foods In Persons with Type 2 Diabetes Mellitus (DEGIF4). Diabetes 2007; 56(Suppl 1) (Abstract).

27. Chlup R, Kudlová P, Peterson K, Slezáková L, Bartek J, Nakládalová $\mathrm{M}$ et al. Glykemický index potravin u osob s diabetem 1. a 2. typu a u zdravých. Diabetes a obezita 2007; 7(13):78-89.

28. Chlup R, Kudlová P, Sečkař P, Zapletalová J, Bartek J, Chlupová $\mathrm{K}$ et al. Glycaemic index of foods in healthy persons vs persons with type 1 diabetes mellitus. Diabetes 2006; 55(Suppl 1):A593 (Abstract).

29. Chlup R, Jelenová D, Kudlová P, Bartek J, Nakládalová M, Sečkař $P$ et al. Konventionelle Bestimmung des glykämischen Indexes verschiedener Nahrungsmittel (Schokolade, Apfelmuss, Reisbrot, Yoghurt) bei pumpenbehandelten Typ-1 Diabetikern. Diabetologie und Stoffwechsel 2006; 1(Suppl 1):154 (Abstract).

30. Chlupová K, Kohnert KD, Heinke P, Augstein P, Chlup R, Salzsieder E. Resultate kontinuierlicher Glukosemessungen (CGMS) unter ambulanten Bedingungen zur Beurteilung der Stoffwechseleinstellung bei T2DM. Diabetologie und Stoffwechsel 2006; 1(Suppl 1):94 (Abstract).

31. Mlčák P, Fialová J, Trnková K, Chlup R. A continous glukose monitoring system (CGMS) - A promising approach for improving metabolic control in persons with type 1 diabetes mellitus treated by insulin pumps. Biomed. Papers 2004; 148:33-38.

32. Chew I, Brand JC, Thorburn AW, Truswell AS. Application of glycemic index to mixed meals. Am J Clin Nutr 1988; 47(1):53-6.

33. Kudlová $\mathrm{P}$, Stanislavová A. Edukace zdravých probandů v souvislosti s určováním glykemického indexu potravin (Czech: Education of healthy volunteers for the determination of glycemic index of foods). $1^{\text {st }}$ ed. In: Čáp J, Žiaková K, Nemčeková M, Holmanová E, ed. Teoria, výskum a vzdelávanie $\mathrm{v}$ ošetrovatelstve (Theory, research and education in nursing). Univerzita Komenského Bratislava, Jeseniova Lekárska Fakulta Martin, Ústav ošetrovatelstva, SR, Lékařská fakulta Univerzity Palackého Olomouc, Ústav teorie a praxe ošetřovatelství, ČR, Občianské združenie pre rozvoj zdravotníckeho vzdelávania v Martine. 2005:363-372. 
